$\widetilde{S}_{\text {https://doi.org/10.3765/sp.9.13 }}^{\text {Semantics \& Pragmatics Volume 9, Article 13: 1-24, } 2016}$

\title{
A note on the architecture of presupposition*
}

\author{
Matthew Mandelkern \\ Department of Linguistics and Philosophy, MIT
}

Submitted 2015-10-31 / First decision 2015-12-18 / Revision received 2016-01-14 / Accepted 2016-01-25 / Final version received 2016-02-03 / Early access 2016-04-28 / Published 2018-08-30

\begin{abstract}
The Proviso Problem is the discrepancy between the predictions of nearly every major theory of semantic presupposition about what is semantically presupposed by conditionals, disjunctions, and conjunctions, versus observations about what speakers of certain sentences are felt to be presupposing. I argue that the Proviso Problem is a more serious problem than has been widely recognized. After briefly describing the problem and two standard responses to it, I give a number of examples which, I argue, show that those responses are inadequate. I conclude by briefly exploring alternate approaches to presupposition that avoid this problem.
\end{abstract}

Keywords: proviso problem, presupposition, presupposition projection, accommodation, pragmatic strengthening, independence

\section{Introduction}

Nearly every current theory of semantic presupposition predicts that the strongest semantic presupposition of a conditional with the form

(1) If $\mathrm{p}$ then $\mathrm{q}_{r} \cdot{ }^{1}$

* I am grateful to Danny Fox and Irene Heim for invaluable feedback on this paper. I am also grateful to audiences at MIT and the 'Going Heim' conference at the University of Connecticut, two anonymous reviewers for Semantics and Pragmatics, David Boylan, Cleo Condoravdi, Nilanjan Das, Kai von Fintel, Cosmo Grant, Samia Hesni, Matthias Jenny, Justin Khoo, Milo Phillips-Brown, Kevin Richardson, Daniel Rothschild, Ginger Schultheis, Robert Stalnaker, Stephen Yablo, and Martín Abreu Zavaleta for very helpful discussion.

1 Subscripts indicate the semantic presuppositions of atomic presupposition bearers. Roman letters and strings stand for sentences, and italic letters and strings stand for the

(C)2016 Matthew Mandelkern

This is an open-access article distributed under the terms of a Creative Commons Attribution License (https://creativecommons.org/licenses/by/3.o/). 
Matthew Mandelkern

is the material conditional

(2) $\quad \mathrm{p} \supset \mathrm{r}$.

It is well known that this prediction does not line up neatly with observations about what someone who asserts a conditional with the form of (1) is often felt to be presupposing. For instance, someone who asserts

(3) If Theo hates sonnets, then so does his wife. ${ }^{2}$

is felt to presuppose

(4) Theo has a wife.

However, most current theories of presupposition predict that (3) semantically presupposes just the material conditional

(5) Theo hates sonnets $\supset$ Theo has a wife.

rather than the unconditional (4). Similar patterns arise for semantic presuppositions triggered in right disjuncts and conjuncts.

The discrepancy between the predicted conditional semantic presupposition of a sentence like (3) and the unconditional proposition which a speaker of a sentence like (3) is felt to presuppose is known as the Proviso Problem. ${ }^{3}$ This problem was recognized early in the development of theories of presupposition that make the relevant conditional predictions, ${ }^{4}$ and a fair amount of recent work has aimed to address it. Although there are differences in detail, almost all of that work pursues the same general strategy: a sentence like (3) semantically presupposes the conditional (5), but, on the basis of pragmatic reasoning, interlocutors conclude that a speaker of a sentence like (3) is pragmatically presupposing something stronger, namely, the corresponding unconditional (in this case, (4)). Some of that work further

corresponding propositions. Sentences presuppose other sentences (or propositions) semantically; speakers presuppose sentences (or propositions) pragmatically in the sense of taking that sentence or proposition to be common ground (see Stalnaker 1970). It will be obvious from context which use of 'presuppose' is intended, but the two notions should be kept clearly distinct. In what follows I make standard assumptions about the presuppositions of possessives, definite descriptions, clefts, and factives.

2 Modified slightly from Geurts 1996.

3 Following Geurts 1996.

4 At least since Karttunen \& Peters 1979. 
Architecture of presupposition

argues that speakers reach this conclusion just in case the consequent of the conditional in question is in some sense independent of its antecedent.

In this paper I argue that these broadly pragmatic lines of response to the Proviso Problem are inadequate. I begin by explaining the responses in more detail. Then I give a variety of cases in which speakers are felt to presuppose something unconditional even though the consequent of the predicted conditional presupposition depends on its antecedent in ordinary ways and there is no apparent independent source of pragmatic pressure to conclude that the speaker is presupposing something unconditional. While cases like this have been observed previously, they have been largely neglected in the literature. These cases raise a prima facie challenge to the standard lines of response to the Proviso Problem. I proceed to sharpen this challenge by giving a novel kind of case in which speakers are felt to presuppose the relevant unconditional even though there is strong pragmatic pressure to take them only to be presupposing the predicted conditional presupposition. I conclude that, in their current form, pragmatic approaches do not solve the Proviso Problem.

\section{C-theories}

The predictions that lead to the Proviso Problem are as follows: ${ }^{5}$

(6) If $\mathrm{p}$ then $\mathrm{q}_{r}$.

$\leadsto \mathrm{p} \supset \mathrm{r}$

(7) $\quad \mathrm{p}$ or $\mathrm{q}_{r}$.

$\leadsto \neg \mathrm{p} \supset \mathrm{r}$

(8) $\mathrm{p}$ and $\mathrm{q}_{r}$.

$$
\leadsto \mathrm{p} \supset \mathrm{r}
$$

For ease of discussion, I will focus on the first of these predictions, but everything I say extends equally to the others.

I will refer to the class of theories that make predictions (6)-(8) as $c$ theories ('c' for conditional). ${ }^{6}$ This class is wide and diverse enough that it is easiest to delimit by exclusion rather than inclusion: nearly every major theory of semantic presupposition makes these predictions, with the notable exception of the theory developed within the framework of discourse

5 With 'm' standing for 'semantically presupposes'.

6 The name is not meant to suggest an underlying structural similarity to the theories. 
representation theory $(D R T) .^{7}$ The class of c-theories thus includes, most significantly, satisfaction theory, ${ }^{8}$ as well as multivalent theories ${ }^{9}$ and a variety of other theories. ${ }^{10}$

\section{Responses to the Proviso Problem}

The Proviso Problem, again, is the discrepancy between the predictions of c-theories about the semantic presuppositions of conditionals, versus the stronger, unconditional proposition that a speaker of a conditional is often felt to presuppose. The existence of this gap - illustrated by examples like (3) - is not per se an objection to c-theories. But insofar as c-theories are meant to play a central role in a larger theory that accounts for what speakers are typically felt to be presupposing when they assert certain sentences, it is incumbent on defenders of c-theories to spell out how to bridge this gap.

There is no in-principle objection to the viability of such a story. It is open to defenders of c-theories to argue that conditional sentences always have conditional presuppositions, but that in some cases, for systematic pragmatic reasons - reasons not specific to the domain of natural language - a speaker of a conditional is felt to presuppose strictly more than that conditional's semantic presuppositions. This is the basic architecture of almost every extant response to the Proviso Problem on behalf of c-theories. ${ }^{11}$ Spelled out in slightly more detail:

7 van der Sandt 1989, 1992, Geurts 1996, 1999, Kamp 2001, and others. See below for brief discussion of some other theories that avoid these predictions.

8 Satisfaction theory (the sobriquet is Geurts's (1996)) is spelled out in Heim 1982, 1983, 1990, 1992, based on earlier work in Stalnaker 1973, 1974, Karttunen 1974, and since developed in Beaver 2001, von Fintel 2008, Schlenker 2009, Rothschild 2011, and others.

9 Kleene 1952, Strawson 1952, van Fraassen 1969, Peters 1977, Karttunen \& Peters 1979, and more recently George 2008, Fox 2012.

10 E.g., Soames 1982, Schlenker 2008, Chemla 2008.

11 Stories of this kind have been sketched for instance in Karttunen \& Peters 1979, Soames 1982, Heim 1990, Beaver 1992, 1999, 2001, Heim 2006, van Rooij 2007, Singh 2007, 2008, von Fintel 2008, Fox 2011, Schlenker 2011, Lauer 2014. It is compatible with Basic Architecture that the pragmatic reasoning in question is supported by a structured set of alternatives that draws on more than purely pragmatic reasoning, as in the proposals of Schlenker and Singh. Basic Architecture, as well as Independence, generalizes in obvious ways to conjunctions and disjunctions. 
Architecture of presupposition

(9) Basic Architecture: Conditionals always have conditional presuppositions; but when $\mathrm{S}$ asserts a conditional of the form ' If $\mathrm{p}$ then $\mathrm{q}_{r}{ }^{7}$, her listener compares the relative plausibility of

\section{i. $\mathrm{S}$ is presupposing just $p \supset r,{ }^{12}$ versus}

ii. $\mathrm{S}$ is presupposing $r$.

Her listener will conclude in favor of Option ii iff she has pragmatic reasons to think that Option ii is more plausible. ${ }^{13}$

A closely related line of response runs as follows:

(10) Independence: Conditionals always have conditional presuppositions;

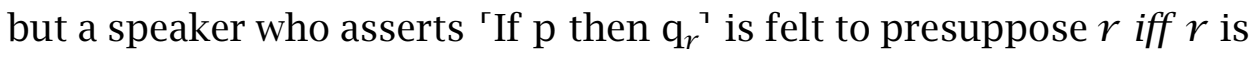
in some sense independent of $p$; otherwise, she is felt to presuppose only $p \supset r$.

It is natural to view Independence as an elaboration of Basic Architecture: there is something weird about a conditional whose consequent is independent of its antecedent, and this weirdness gives us pragmatic reason to think that the speaker is not presupposing (just) that conditional. In the absence of this pressure, however, we take the speaker only to be presupposing the relevant conditional. However, some have also defended Independence without taking on board Basic Architecture, ${ }^{14}$ and one could certainly take on board the latter without the former; for this reason I will treat them separately in what follows. One could also defend a combination of the views, so that presupposed conditionals get strengthened iff they are independent or there are other pragmatic pressures to do so. This would amount to one way of spelling out Basic Architecture in more detail, and so I will not treat this as a separate view in what follows; insofar as my arguments tell against Basic Architecture, they tell against this combination of views as well.

12 In addition, of course, to any unrelated propositions she is felt to be presupposing.

13 And reason to think that this is common ground. Spelled out in slightly more detail: Option i says that $\mathrm{S}$ accepts that after she makes her assertion, but before it is evaluated, $p \supset r$, but not $r$, will be common ground; Option ii says that $\mathrm{S}$ accepts that at that time $r$ will be common ground. See Stalnaker 2002 and von Fintel 2008 for relevant discussion of speaker presupposition and accommodation. This kind of story is due in particular to Heim 2006; similar proposals can be found especially in the works of Beaver, von Fintel, and Singh cited above.

14 See especially Pérez Carballo 2009 and Lassiter 2012. 
The notion of independence which plays a central role in Independence can be specified in a number of ways, as long as the specification fits into a broader explanatory strategy..$^{15}$

There are two main candidates in the literature. The first spells out independence in terms of probabilistic independence: $r$ is independent of $p$ in this sense at a context $c$ just in case $P r_{c}(r) \approx P r_{c}(r \mid p)$, where $P r_{c}(\cdot)$ is a contextually relevant probability measure. ${ }^{16}$ A second approach, given in Pérez Carballo 2009, spells out independence in terms of the selection function associated with a Stalnaker conditional; call this sense of independence conditional independence. ${ }^{17} r$ is conditionally independent of $p$ at a context just in case the context's selection function includes a $\neg r$-world among the closest $p$-worlds for any $(\neg p \wedge \neg r)$-world in the context set.

The responses just summarized look promising when it comes to examples like the one we began with. There is a natural sense in which the consequent of

(5) Theo hates sonnets $\supset$ Theo has a wife.

15 One inadmissible specification of 'independent' is thus: $r$ counts as independent of $p$ in $c$ iff, when $p \supset r$ is semantically presupposed by a conditional in $c$, it gets strengthened to $r$. This is inadmissible for our purposes since it is obviously not explanatory. For this reason I will not consider the view given in van Rooij 2007 here, since this is what his view seems to amount to (for more discussion, see Mandelkern \& Rothschild 2018).

16 This is the view endorsed in Schlenker 2011, citing Singh 2006; Lassiter 2012 endorses a similar view, according to which strengthening takes place just in case $\operatorname{Pr}_{c}(r) \geq P r_{c}(r \mid p)$. 'Strengthened' or 'strengthened/unconditional reading' is a bit of sloppiness that I will go in for here: of course the proposal is not that the semantic presupposition is replaced by something stronger, but rather that something stronger (namely, the relevant unconditional) is assumed to be presupposed by the speaker.

17 See Stalnaker 1968. Pérez Carballo's argument turns crucially on the assumption that presupposed conditionals are Stalnaker conditionals, not material conditionals. I will continue to assume, contrary to Pérez Carballo but with most of the literature, that the conditional presuppositions in question are material conditionals (though in discussion I will sometimes approximate these with natural language conditionals). This assumption may be wrong, and Irene Heim (p.c.) has suggested to me that careful attention to the way that conditional presuppositions inherit the "flavor" of the asserted conditional may help explain some of the data given below in a way friendly to c-theories. But my main points still go through if we follow Pérez Carballo in amending this assumption. A simple way to see this, pointed out to me by Pérez Carballo, is that the points I make here can be extended to disjunctions and conjunctions, but it is uncontroversial that, according to c-theories, disjunctions and conjunctions presuppose material conditionals, not Stalnaker conditionals. 
Architecture of presupposition

looks probabilistically and conditionally independent of the antecedent in most contexts (although I admit that I am not exactly sure how to evaluate these metrics). Independence thus seems to rightly predict that someone who asserts

(3) If Theo hates sonnets, then so does his wife.

is felt to presuppose that Theo has a wife. A similar line of reasoning could be spelled out within the more general framework of Basic Architecture.

There are many theoretical questions to ask about Basic Architecture and Independence. ${ }^{18}$ There has been substantial work done towards answering many of these questions in the papers cited above, and I would like to grant, for the sake of argument, that they can be answered. The point I will make here is that, even setting aside these theoretical worries, neither Independence nor Basic Architecture provides an empirically adequate solution to the Proviso Problem.

\section{Unexpected strengthening}

Trouble begins when we attend to a broader range of examples: examples in which a conditional presupposition is strengthened even though, first, the presupposition's consequent straightforwardly depends on its antecedent, and, second, there is no apparent independent source of pragmatic pressure to strengthen the presupposition. Examples like these have been discussed before, in Gazdar 1979 and Geurts 1996, 1999, but mostly neglected otherwise. ${ }^{19}$ The goal of this section and the next is to show that these examples continue to be problematic for the main responses which have been developed to the Proviso Problem: in particular, I argue that they make serious trouble for Independence, and at least pro tanto trouble for Basic Architecture. In Section 6 I give novel variants on these examples to make a more decisive case against Basic Architecture.

18 See especially Geurts 1996; Geurts notes that someone who asserts a factive construction like 'Susie knows that if Theo hates sonnets, he has a wife' is felt to presuppose only the (independent) conditional 'If Theo hates sonnets, he has a wife,' not the strengthened 'Theo has a wife.' Proponents of the present theory thus must explain why the predicted pragmatic strengthening is blocked in cases like this.

19 Though see Soames 1982 and van Rooij 2007. 
Matthew Mandelkern

\subsection{Smith's murder}

Consider:

(11) [It is common ground that Smith has gone missing, and we don't know whether he is still alive. A detective enters and says:] If the butler's clothes contain traces of Smith's blood, then it was the butler who killed Smith.

The detective is felt to presuppose Someone killed Smith.

This is confirmed by my intuitions, by informants, and further by the 'Hey wait a minute' (HWAM) test:

(13) Hey wait a minute! I didn't know someone killed Smith!

The felicity of a HWAM response indicates that the speaker has committed herself to the content in question. The felicity of (13) as a response to (11) thus suggests that the speaker of (11) has indeed committed herself to (12).

Now consider the predictions of the accounts sketched in the last section. According to c-theories, (11) semantically presupposes:

(14) The butler's clothes contain traces of Smith's blood $\supset$ Someone killed Smith.

The consequent of (14) depends in a straightforward way on its antecedent. Finding out that the butler's clothes contain traces of Smith's blood typically should, and will, raise our credence that Smith was killed. ${ }^{20}$ Thus Independence wrongly predicts that the speaker's interlocutors will take the speaker of (11) to be presupposing (14) alone, and not the stronger (12).

Independence thus makes the wrong prediction; does the more general Basic Architecture do better? It is harder to assess the predictions of this view, but it does not seem to me that it does any better. To assess this, we must ask whether, when interlocutors compare

20 The consequent is plausibly conditionally dependent on the antecedent as well, though it is hard to know how to get direct intuitions about this; in any case, this is true if conditional independence is meant to track our intuitions about relevance, evidence, and causal relations, as I take it it is. 
Architecture of presupposition

(15) The detective is presupposing Someone killed Smith.

versus

(16) The detective is presupposing The butler's clothes contain traces of Smith's blood $\supset$ Someone killed Smith.

they have general pragmatic reason to conclude in favor of the former, rather than the latter. ${ }^{21}$ It is hard to see what pragmatic pressure there is to draw this conclusion. When it comes to an example like (3), defenders of Basic Architecture reason as follows:

The addressee asks what the speaker must be presupposing... in order for the event to be a cooperative contribution to the conversation. It would be absurdly implausible for the addressee to hypothesize that the speaker must have been presupposing that either Theo doesn't hate sonnets or is married, but not presupposing either of the disjuncts. (Stalnaker 2014: 69)

By contrast, in the present case it is perfectly plausible to think that the speaker is presupposing

(14) The butler's clothes contain traces of Smith's blood $\supset$ Smith was killed.

without presupposing the consequent or the negation of the antecedent. Indeed, (14) seems like a fairly natural working hypothesis to attribute to the detective - and, moreover, one that we can imagine her assuming without making explicit.

\subsection{An explanation from redundancy?}

Considerations of overall plausibility thus do not seem to help here. A slightly different approach to explaining why (14) gets strengthened to (12) is

21 Reasons apart, of course, from the fact that they know that a speaker of (11) is typically presupposing (12). It is worth emphasizing that it is of course true that (15) is more plausible than (16), and moreover that this is common knowledge among ordinary speakers, but these are not facts that we can appeal to in explaining the data: these facts are precisely what we are trying to explain. 
to appeal to general considerations about conversational practices. ${ }^{22}$ There are different ways of pursuing this strategy; I will discuss here the route that looks most promising to me, and argue that it does not succeed.

This route, suggested to me by an anonymous reviewer for this journal, argues that considerations about redundancy can explain the pressure towards a strengthened, unconditional reading in cases like (11). The idea is that, in order to be felicitous, a speaker's assertion must provide a sufficient amount of new information, over and above what the speaker presupposes and what we can gather from her presuppositions. ${ }^{23}$ Suppose, in the present case, that we take the speaker to be presupposing only (14). It is natural to assume that the speaker knows (14) because she knows that if the butler's clothes contain traces of Smith's blood, then the butler killed Smith. If we can gather this from (14), however, then the asserted content of (11) would add nothing new beyond what we can gather from what the speaker presupposes. By contrast, suppose we take the speaker to be presupposing (12). Then (even though (12) entails (14)) there won't be any reason to conclude that the speaker knows (12) on the basis of knowing that if the butler's clothes contain traces of Smith's blood, then the butler killed Smith (since this is, of course, not by itself a basis for knowing that Smith was killed). Thus the asserted content of (11) does indeed add something substantial beyond what we can gather from the speaker's presuppositions, and this contrast pressures us to interpret the speaker as presupposing (12) rather than just (14).

The first way to evaluate this proposal is to test whether the relevant sequence really does strike us as objectionably redundant by transforming it into a sequence of assertions. Compare:

(17) Smith is dead; and if the butler's clothes contain traces of Smith's blood, then it was the butler who killed him.

versus

(18) If the butler's clothes contain traces of Smith's blood, then Smith is dead, and it was the butler who killed him. ${ }^{24}$

22 An avenue suggested to me by Irene Heim.

23 Or it must serve some other coordinating purpose, e.g., adding discourse referents.

24 Or equivalently: 'If the butler's clothes contain traces of Smith's blood, then Smith is dead, and if the butler's clothes contain traces of Smith's blood, then it was the butler who killed Smith.' This version sounds fine as well, if verbose. Since the relevant question for us is about informational redundancy, and not verbosity, it seems to me that (18) is a better test sentence; but I believe the present point goes through either way. Note that all three versions 
Architecture of presupposition

The present proposal leads us to expect that (18) will strike us as infelicitously redundant, whereas (17) will not. But I do not detect any such contrast here, nor do any informants I have run the pair by. This suggests that the present line of reasoning is mistaken. Perhaps from (14) we can surmise that the speaker is assuming that if the butler's clothes contain traces of Smith's blood, then the butler killed Smith; but it is nonetheless unproblematic for the speaker to proceed to assert what we have so far only surmised.

The fact that no intuition of redundancy surfaces when we test these sequences provides some evidence that considerations about redundancy do not play any role in pressuring interlocutors to strengthen (14) to (12), and analogous tests point to the same conclusion in the cases I give below. Nonetheless, it is possible that our judgments about these sequences change when we translate them from a presupposition plus assertion (as in the original case) to a series of assertions (as in the pair just given), and so we should not treat this test as decisive.

We can, however, strengthen our case against the redundancy line of reasoning by modifying our example slightly to ensure that the asserted content adds substantial new information under both a conditional and an unconditional reading. Consider this variant on (11):

(19) [It is common ground that Smith went missing last week, and we don't know whether he is still alive. A detective enters and asserts:] If the butler's clothes contain traces of Smith's blood, then we'll soon have Smith's murderer behind bars.

According to c-theories, (19), like (11), presupposes the conditional (14); but a speaker of (19) is felt to presuppose the unconditional (12), just as for (11). In this case, though, a redundancy-based story to explain the strengthening of (14) to (12) does not get off the ground. Suppose that, on first hearing (19), we take the speaker to be presupposing only (14). Then we may well reason that she is presupposing this because she knows that if the butler's clothes contain traces of Smith's blood, then the butler killed Smith. But even if we can conclude this from her (conditional) presupposition, in this case the asserted content still adds something new: namely that we would have no trouble catching and arresting the butler. Thus there is no way to trace

are still felicitous with 'moreover' substituted for 'and', which further confirms the intuition that these sequences are non-redundant (the 'moreover' test is attributed to class notes by Orin Percus). 
a preference for an unconditional interpretation of (19) to a desire to avoid interpreting the speaker as being redundant.

Of course, these considerations about (19) do not give us decisive evidence about what pressures us towards an unconditional reading in (11), but it strikes me as implausible that different mechanisms explain the strengthening in these two cases. In any case, we could simply focus on cases like (19) to make our case against Basic Architecture. ${ }^{25}$

I conclude that the present line of response does not explain the strengthening of the presupposition of (11). I do not see a more promising approach, and thus I do not see how to account for a case like this within the framework of Basic Architecture. This does not mean there is no way to do so: it is impossible to rule out that there is an explanation I am overlooking. My point for now is simply that it is incumbent on defenders of c-theories to give an explanation of cases like this, and that it is not clear how it would go. ${ }^{26}$

25 To make good on this, in what follows, wherever a worry about redundancy could be raised, I footnote a variant of the case that controls for that worry.

26 A different way of attempting to use general conversational practices to explain the strengthening in question is to argue that, were we to impute to the detective the intention to communicate only the conditional (14), we would treat her as presupposing something that addresses an implicit question under discussion (QUD): something like how can we find out whether Smith was killed? This kind of conversational move is generally marked: QUDs should be addressed by asserted, not presupposed, content. And so there is pressure to avoid treating the speaker as presupposing (14). This line of response is fairly easy to dismiss, however. Two observations are key here. First, (12) entails (14). Thus if (14) answers QUDs in an objectionable way, then so does (12). Of course, this line of argument only goes through if, as we are assuming, the presupposed conditional is a material conditional. But even if we abandon that assumption, note that, second, in addition to whatever QUDs (12) answers insofar as it entails (14), (12) also answers a further QUD: whether Smith is dead. Thus, if the conditional reading of (11) were infelicitous on the grounds that it answers a QUD with presupposed content, we would expect the unconditional reading to be even less acceptable, since (12) answers every QUD that (14) does, and more. It follows, first, that we cannot explain a selectional pressure for the unconditional over the conditional reading on the grounds of the present considerations; if there is infelicity in this case having to do with QUDs, then, if anything, this infelicity would pressure us towards the conditional rather than the unconditional reading of (11), since the conditional answers strictly fewer QUDs than the unconditional. But, second, the unconditional reading of (11) is perfectly felicitous; since the unconditional reading inherits any QUD-related infelicity of the conditional reading, it follows that there is no QUD-related infelicity for the conditional reading in the first place. 
Architecture of presupposition

\section{More cases}

In this section I will give a number of examples similar to (11) and (19). In all these cases, the consequent of the predicted conditional presupposition depends on its antecedent in ordinary ways, but nonetheless the speaker is felt to take for granted the relevant unconditional. Thus Independence makes the wrong predictions in each case. Moreover, it is hard to see how a pragmatic story along the lines of Basic Architecture would explain the relevant strengthenings. ${ }^{27}$ A redundancy-based approach will not work, for the reasons sketched in the last section; and I do not see a more plausible alternative.

I multiply cases here for two reasons. One is to reduce the likelihood of unintended confounds in the cases given above. The other is to control for a possible response to the present cases which holds that we can explain them simply by cashing out the notion of "independence" in a different way. The breadth of examples given here makes it hard to see how we can specify a notion of independence which is sufficiently broad for Independence to make the right predictions, but still fits naturally into a broader, explanatory theory of communication.

\subsection{Diabetes}

(20) a. Is John in good health? Is he taking care of himself?

b. [I'm not sure, but we should be able to tell at dinner; if he's restricting his sugar intake, then his diabetes is under control.

A speaker of (2ob) will typically be felt to presuppose

(21) John has diabetes.

This is confirmed by intuitive judgments, as well as by the HWAM test. But according to c-theories, (2ob) presupposes the conditional

(22) John’s restricting his sugar intake $\supset$ John has diabetes.

27 To evaluate this, of course, we need to spell out the contexts in which these utterances are made; I give brief suggestions about this in what follows. One important point about these examples, and the contexts I give for them, is that the inference I report is merited even when the unconditional proposition in question is not already common ground before the utterance. These examples thus are not vulnerable to the confound discussed in Katzir \& Singh 2013. 
In ordinary contexts, the consequent of this conditional seems to depend in straightforward ways on the antecedent, and so Independence wrongly predicts that (22) will not be strengthened to (21). Nor is it easy to see how pragmatic considerations will lead to the conclusion that the speaker is presupposing (21) rather than just (22).

\subsection{Coats}

(23) a. Why did some of the professors wear waterproof coats to work today?

b. [I don't know who did, and I can't tell you for all of them, but] if Jack wore his waterproof coat to work today, then he's aware that it's raining out. ${ }^{28}$

A speaker who asserts (23b) will typically be felt to presuppose

(24) It's raining out.

According to c-theories, (23b) presupposes

(25) Jack wore his waterproof coat to work today $\supset$ It's raining out.

The consequent of (25) is not independent of its antecedent in any relevant sense, and so Independence wrongly predicts that it will not be strengthened to (24). And again, it is hard to see how broadly pragmatic considerations help explain this strengthening.

\subsection{Baseball}

(26) a. What were the kids up to today?

b. [I don't know, but] if they were playing baseball in the backyard earlier, then they're the ones who broke the dining room window. ${ }^{29}$

Someone who asserts (26b) is typically felt to presuppose

28 A variant that controls for issues about redundancy: ‘[I don't know who did, and I can't tell you for all of them, but] if Jack wore his waterproof coat to work today, then his stepsister isn't aware that it's raining out. (She tries to sabotage his health by hiding his jacket when it rains.)'

29 A variant that controls for issues about redundancy: '[I don't know, but] if they were playing baseball in the backyard earlier, then it wasn't Aaron who broke the dining room window.' 
Architecture of presupposition

(27) Someone broke the dining room window.

C-theories predict that the semantic presupposition of (26b) is

(28) The kids were playing baseball in the backyard earlier $\supset$ Someone broke the dining room window.

The consequent of (28) is not independent of its antecedent in any relevant sense, and so Independence wrongly predicts that it will not be strengthened to (27). And, again, it is hard to see how Basic Architecture helps here.

\section{Strengthening the case against Basic Architecture}

The considerations discussed up to this point constitute a strong case against Independence, but only a pro tanto case against Basic Architecture: all they show is that there are cases where it is unclear how Basic Architecture can explain the data, and where an explanation is needed. This falls far short of a clear argument that Basic Architecture is untenable. As I show in this section, however, we can modify those cases to give a more probative argument against Basic Architecture.

According to Basic Architecture, strengthening takes place through domain-general pragmatic reasoning. Strengthening should thus be blocked when there is strong pragmatic pressure against interpreting a speaker as being committed to the relevant unconditional. But, as I show here, in some cases the conditional presupposition posited by c-theories gets strengthened even in the face of strong pragmatic pressure not to strengthen it. ${ }^{30}$

The following variant on (11), suggested to me by Danny Fox, illustrates this point:

(29) [It is common ground that Susie has disappeared. The detective says:] We don't know where Susie is, or even whether she's still alive. We need to examine her room.

30 Geurts (1996: §3) makes a related point in his third objection to the Argument from truthfunctionality. Geurts's cases differ from mine in that in his cases, the speaker asserts the negation of the unconditional rather than avowing ignorance of it. This difference strikes me as important, because it seems like the c-theorist will be able to explain on independent grounds what is wrong with presupposing $p \supset q$ and then denying $q$ (and thereby communicating in a very roundabout way that $p$ is false). No similar explanation is available in the case in which the speaker simply avows ignorance of $q$ rather than denying it. 
a. If there are bloodstains in the room, then Susie was murdered, and Susie's murderer did a sloppy job.

b. If there are bloodstains in the room, then Susie's murderer did a sloppy job. ${ }^{31}$

(29a) is a good continuation. But (29b) is quite peculiar. Intuitively the source of the peculiarity is that in asserting (29b), the detective is presupposing that Susie was murdered, contrary to his prior assertion that he doesn't know this.

There are two ways to confirm that this is, indeed, what accounts for the oddity of (29b). First, note that

(30) Hey wait a minute! I thought that we didn't know whether Susie was murdered or not!

is a felicitous response to (29b), which suggests that the speaker of (29b) does indeed communicate that Susie was murdered.

Second, compare a minimal variant of (29b) in which the speaker does not deny that she knows whether Susie was murdered:

(31) [It is common ground that Susie has disappeared. The detective says:] We need to examine Susie's room. If there are bloodstains in the room, then Susie's murderer did a sloppy job.

(31) is felicitous. This suggests, again, that what renders (29b) unacceptable is the tension between the detective's avowal of ignorance about whether Susie was murdered, and her felt presupposition that Susie was murdered.

These tests confirm the intuition that the speaker of (29b) is felt to presuppose that Susie was murdered. But this looks like the opposite of what Basic Architecture predicts. According to c-theories, the semantic presupposition of (29b) is:

(32) There are bloodstains in the room $\supset$ Susie was murdered.

According to Basic Architecture, (32) can get strengthened to

(33) Susie was murdered.

31 A variant that controls for worries about redundancy: 'If there are bloodstains in the room, then Susie's murderer is in prison as we speak. (We picked up a notoriously sloppy serial murderer yesterday.)' 
Architecture of presupposition

if there is pragmatic pressure to do so. As with the examples above, it is hard to find reasons which would favor this interpretation. ${ }^{32}$ But here we can make a stronger point. Even if we are overlooking subtle pragmatic reasons that tell in favor of strengthening (32) in this case, they should be overwhelmed by the strong and general pragmatic pressure to interpret speakers as having coherent commitments. But we can only interpret the speaker of (29b) as having coherent commitments if we do not strengthen (32). For if we strengthen (32), we take the speaker to be committed to the propositions, first, that Susie was murdered, and second, that she doesn't know whether Susie was murdered, commitments which are incoherent. ${ }^{33}$ By contrast, if we take the speaker to be committed only to (32), then we can interpret her as coherent: we will hear her as committed to exactly the information expressed in (29a), which is felicitous. The prediction of Basic Architecture in this case thus seems clear: namely, that (32) will not be strengthened to (33). This is the wrong prediction.

Examples like (32) can be multiplied by giving appropriate contexts for cases of the kind discussed earlier in this paper. For instance, consider this variant of (20):

(34) a. [Tim:] I haven't seen John in forever. I heard he has either diabetes or arthritis. Do you know whether whatever he has is under control?

b. [Jason:] I'm not sure; I actually don't know what sickness he has, either. But we should be able to tell by what he eats tonight.

(i) If he restricts his sugar intake, then he has diabetes, but it's under control.

(ii) If he restricts his sugar intake, then his diabetes is under control.

(34b-ii) is infelicitous here. As in the case of (29b), we can diagnose this as follows: Jason is felt to be presupposing what he has just said he doesn't know, namely that John has diabetes. This is confirmed by the fact that (35) is a felicitous response to (34b-ii):

(35) [Tim:] Wait a minute! So he does have diabetes? I thought you just said you don't know what sickness he has?

32 Again, for the reasons given in Section 4, considerations about redundancy or QUDs will not help explain the case.

33 In the sense in which Moore-paradoxical sentences are incoherent. 
Once more, however, this does not match the prediction of Basic Architecture. C-theories predict that (34b-ii) presupposes

(36) John restricts his sugar intake $\supset$ John has diabetes.

Basic Architecture predicts that (36) can be strengthened to

(37) John has diabetes.

if there is pragmatic pressure to do so. But we can preserve the coherence of Jason's discourse in this case only if we attribute to him just (36), and not the stronger (37). In light of the strong, general pragmatic pressure to interpret speakers as being coherent, Basic Architecture thus predicts that in asserting (34b-ii), Jason is taken to presuppose only the conditional (36), not the unconditional (37). But again, this is the wrong prediction: Jason is taken to presuppose (37).

\section{Prospects}

I conclude that neither Independence nor Basic Architecture is by itself an empirically adequate solution to the Proviso Problem. Nor will a combination of these two approaches do any better, since such a combination would inherit the problems for Basic Architecture sketched in the last section.

Before surveying a few possible avenues of response to the data I have given, I note a key point that must be accounted for by any approach. I have given cases in this paper where a conditional reading is felt to be unavailable, but there are other, structurally very similar, cases where a conditional reading is felt to be available. For instance, consider

(38) [It is common ground that there has been a monarchist rebellion in Ukraine. An intelligence analyst says:] We don't know whether Ukraine has a king now or not. We need to consult our agents on the ground. If the monarchist rebellion succeeded, then we need to make contact with the new king of Ukraine as soon as possible.

(38) is structurally very similar to (29b) and (34b-ii). But, by contrast to those cases, (38) does not strike us as incoherent: it seems that here we are willing to accept a conditional reading of the semantic presupposition of (38). That is, we are able to hear the speaker as committed only to the conditional 
Architecture of presupposition

(39) The monarchist rebellion succeeded $\supset$ There is a king.

and not committed to the unconditional

(40) There is a king.

Note that (39) is non-trivial, since monarchies may have kings or queens, and so some accommodation is required in this case. Yet, in contrast to the cases discussed above - and in keeping with the predictions of Basic Architecture and Independence - in this case we do not strengthen the conditional (39) to the unconditional (40).

What is surprising, and worth emphasis here, is the existence of both cases like those I gave above, where strengthening seems obligatory, and cases like (38), where it isn't. Cases like (38) have, of course, long been known in the literature, and used to defend the predictions of c-theories; in developing a response to the data given above, it is important to bear in mind that, in cases like this, c-theories seem to get things right.

If c-theories are to be defended, however, it looks like a new approach must be developed, either in concert with one of the two approaches discussed above or in place of them. An implicit assumption of Basic Architecture is that presupposition accommodation will be as minimal as possible - that is, that a speaker will be felt to presuppose exactly what is semantically presupposed by what she says, unless there is some pragmatic pressure to assume that she is presupposing something stronger. One way to defend c-theories would be to reject this minimality assumption. The minimality assumption fits very naturally into a broader theory of communication, however, and thus if we reject it, we need to spell out what should go in its place, and how its replacement fits into a larger theory of communication. These tasks look challenging. One approach would be to argue that there is a strong cognitive preference for processing unconditional rather than conditional propositions, a preference strong enough that it can override rational pressure in favor of a conditional interpretation in many cases. If this psychological hypothesis is correct, it should be possible to find independent evidence for it in other domains. ${ }^{34}$

34 One attractive feature of this approach is that it might make sense of the contrast between cases like those discussed here, versus cases like (38) in which a conditional reading is easily available: on a first pass, it looks like we are willing to accept a conditional reading just in case the conditional in question has the status of a common default in reasoning, which fits naturally with this approach. 
A different response to the present considerations is to pursue theories of semantic presupposition that do not make the weak conditional predictions that distinguish c-theories (call such theories non-c-theories). At present there is only one major non-c-theory on the market, namely DRT. DRT has serious open problems of its own, though. ${ }^{35}$ A number of alternative non-ctheories have been developed. Not all avoid the present criticisms, however. In particular, as an anonymous reviewer for this journal points out, theories according to which both a conditional and unconditional presupposition are generated may be able to predict a default unconditional reading, and thus explain the cases given in Sections 4 and 5; but insofar as those theories leave it to pragmatics to select between a conditional and unconditional reading, they cannot explain the cases given in the last section. ${ }^{36}$

\section{References}

Beaver, David. 1992. The kinematics of presupposition. In ITLI prepublication series for logic, semantics and philosophy of language. https://www.illc. uva.nl/Research/Publications/Reports/LP-1992-05.text.pdf.

Beaver, David. 1999. Presupposition accommodation: A plea for common sense. In Larry Moss, Jonathan Ginzburg \& Maarten de Rijke (eds.), Logic, language and computation, vol. 2, 21-44. CSLI Publications: Stanford, CA. https://web.stanford.edu/group/cslipublications/cslipublications/site/ 1575861801.shtml.

Beaver, David. 2001. Presupposition and assertion in dynamic semantics. CSLI Publications: Stanford, CA. http : / / web . stanford . edu / group / cslipublications/cslipublications/site/1575861208.shtml.

Chemla, Emmanuel. 2008. Similarity: Towards a unified account of scalar implicatures, free choice permission and presupposition projection. Manuscript, Ecole Normale Supérieure, Paris and MIT. http://www . emmanuel.chemla.free.fr/Material/Chemla-SIandPres.pdf.

von Fintel, Kai. 2008. What is presupposition accommodation, again? Philosophical Perspectives 22(1). 137-170. https://doi.org/10.1111/j.15208583.2008.00144.x.

35 See Beaver 2001 for a survey.

36 Theories of this kind include one of the views given in Schlenker 2008, as well as Gazdar 1979 and more recent developments of that style of view in Singh 2009, 2015. Views which do seem capable of accounting for both sets of cases include one given in Rothschild 2015, as well as Mandelkern 2016. 
Architecture of presupposition

Fox, Danny. 2011. Notes on the Proviso Problem. Class Notes, 24.954, MIT.

Fox, Danny. 2012. Presupposition projection from quantificational sentences:

Trivalence, local accommodation, and presupposition strengthening. Manuscript. http://lingphil.mit.edu/papers/fox/Quantifier-Projection.pdf.

van Fraassen, Bas. 1969. Presuppositions, supervaluations and free logic. In

Karel Lambert (ed.), The logical way of doing things, 67-92. New Haven: Yale University Press.

Gazdar, Gerald. 1979. Pragmatics: Implicature, presupposition, and logical form. New York: Academic Press.

George, Benjamin Ross. 2008. Presupposition repairs: A static, trivalent approach to predicting projection. University of California, Los Angeles MA thesis. http://www.linguistics.ucla.edu/general/matheses/George_UCLA_ MA_2008.pdf.

Geurts, Bart. 1996. Local satisfaction guaranteed: A presupposition theory and its problems. Linguistics and Philosophy 19(3). https://doi.org/10. 1007/BFoo628201.

Geurts, Bart. 1999. Presuppositions and pronouns. Amsterdam: Elsevier.

Heim, Irene. 1982. The semantics of definite and indefinite noun phrases. University of Massachusetts, Amherst dissertation. http://semanticsarchive. net/Archive/jA2YTJmN/Heim\%2oDissertation\%2owith\%2oHyperlinks . pdf.

Heim, Irene. 1983. On the projection problem for presuppositions. In Michael Barlow, Daniel P. Flickinger \& Nancy Wiegand (eds.), West Coast Conference on Formal Linguistics (WCCFL), vol. 2, 114-125. Stanford University Press. Rpt. as On the Projection Problem for Presuppositions. In Paul Portner \& Barbara H. Partee (eds.), Formal semantics: The essential readings, 24926o. Blackwell, 2002. https://doi.org/10.1002/9780470758335.ch1o.

Heim, Irene. 1990. Presupposition projection. In Rob van der Sandt (ed.), Presupposition, lexical meaning, and discourse processes: Workshop reader. University of Nijmegen. http://semanticsarchive.net/Archive/GFiMGNjN/ Presupp\%2oprojection\%2090.pdf.

Heim, Irene. 1992. Presupposition projection and the semantics of attitude verbs. Journal of Semantics 9(3). 183-221. https://doi.org/10.1093/jos/9.3. 183.

Heim, Irene. 2006. On the proviso problem. Presentation to Milan Meeting, Gargnano.

Kamp, Hans. 2001. Presupposition computation and presupposition justification: One aspect of the interpretation of multi-sentence discourse. 
In Myriam Bras \& Laure Vieu (eds.), Semantics and pragmatic issues in discourse and dialogue, 57-84. Amsterdam: Elsevier. https://brill.com/ view/title/23321.

Karttunen, Lauri. 1974. Presuppositions and linguistic context. Theoretical Linguistics 1(1-3). 181-194. https://doi.org/10.1515/thli.1974.1.1-3.181.

Karttunen, Lauri \& Stanley Peters. 1979. Conventional implicatures in Montague grammar. In Syntax and semantics 11: Presupposition, 1-56. New York: Academic Press.

Katzir, Roni \& Raj Singh. 2013. A note on presupposition accommodation. Semantics and Pragmatics 6(5). 1-16. https://doi.org/10.3765/sp.6.5.

Kleene, Stephen. 1952. Introduction to metamathematics. Amsterdam: NorthHolland.

Lassiter, Daniel. 2012. Presuppositions, provisos, and probability. Semantics and Pragmatics 5(2). 1-37. https://doi.org/10.3765/sp.5.2.

Lauer, Sven. 2014. Biscuits and provisos: Providing unconditional information by conditional means. In Eva Csipak \& Hedde Zeijlstra (eds.), Sinn und Bedeutung (SuB), vol. 19, 357-374. Göttingen. http://semanticsarchive.net/ Archive/TVlN2I2Z/sub19proc.pdf.

Mandelkern, Matthew. 2016. Dissatisfaction theory. In Mary Moroney, CarolRose Little, Jacob Collard \& Dan Burgdorf (eds.), Semantics and Linguistic Theory (SALT), vol. 26, 391-416. https://doi.org/10.3765/salt.v26io.3804. Mandelkern, Matthew \& Daniel Rothschild. 2018. Independence day? Journal of Semantics (forthcoming). https://semanticsarchive.net/Archive/ mEoODYyM/IndependenceDay.pdf.

Pérez Carballo, Alejandro. 2009. Toward a dissolution of the proviso problem. In Paul Egré \& Giorgio Magri (eds.), Massachusetts Institute of Technology Working Papers in Linguistics (MITWPL), vol. 6o, 169-184. http: //perezcarballo.org/files/proviso.mitwpl.pdf.

Peters, Stanley. 1977. A truth-conditional formulation of Karttunen's account of presupposition. In Texas Linguistic Forum 6. University of Texas at Austin.

van Rooij, Robert. 2007. Strengthening conditional presuppositions. Journal of Semantics 24(3). 289-304. https://doi.org/10.1093/jos/ffmoo7.

Rothschild, Daniel. 2011. Explaining presupposition projection with dynamic semantics. Semantics and Pragmatics 4(3). 1-43. https://doi.org/10.3765/ sp.4.3. 
Architecture of presupposition

Rothschild, Daniel. 2015. Truthmakers for semantics and pragmatics: Presupposition and (a little) agreement. Manuscript. http://danielrothschild. com/FabianTruthmaking.pdf.

van der Sandt, Rob. 1989. Presupposition and discourse structure. In Renate Bartsch, Johan van Benthem \& Peter van Emde Boas (eds.), Semantics and contextual expression, 267-294. Foris, Dordrecht.

van der Sandt, Rob. 1992. Presupposition projection as anaphora resolution. Journal of Semantics 9(4). 333-377. https://doi.org/10.1093/jos/9.4.333.

Schlenker, Philippe. 2008. Be Articulate: A pragmatic theory of presupposition projection. Theoretical Linguistics 34(3). 157-212. https://doi.org/10.1515/ THLI.2008.013.

Schlenker, Philippe. 2009. Local contexts. Semantics and Pragmatics 2(3). 1-78. https://doi.org/10.3765/sp.2.3.

Schlenker, Philippe. 2011. The proviso problem: A note. Natural Language Semantics 19(4). 395-422. https://doi.org/10.1007/s11050-011-9072-Z.

Singh, Raj. 2006. A solution to the proviso problem: Formally defined alternatives and relevance. Manuscript, Massachusetts Institute of Technology. Cambridge, MA.

Singh, Raj. 2007. Formal alternatives as a solution to the proviso problem. In Semantics and Linguistic Theory (SALT), vol. 17, 264-281. https://doi.org/ 10.3765/salt.v17io.2960.

Singh, Raj. 2008. Modularity and locality in interpretation. Cambridge, MA: Massachusetts Institute of Technology dissertation. http://hdl.handle. net/1721.1/45895.

Singh, Raj. 2009. Symmetric and interacting alternatives for implicature and accommodation. In Nathan Klinedinst \& Daniel Rothschild (eds.), European Summer School of Logic, Language, and Information (ESSLLI) 2009 Workshop: New directions in the theory of presuppositions. https: //web.archive.org/web/20151207104035/http://web.mit.edu/singhr/ www/singh-esslli-workshop-final.pdf.

Singh, Raj. 2015. Presupposition projection: Global accommodation, local accommodation, and scope ambiguities. Manuscript. https://web.archive. org/web/20170215171622/http://http-server.carleton.ca/ singhr/files/ Global-over-local-2015.pdf.

Soames, Scott. 1982. How presuppositions are inherited: A solution to the projection problem. Linguistic Inquiry 13(3). 483-545. http://www.jstor. org/stable/4178288. 
Stalnaker, Robert. 1968. A theory of conditionals. In Nicholas Rescher (ed.), Studies in logical theory, 98-112. Oxford: Blackwell.

Stalnaker, Robert. 1970. Pragmatics. Synthese 22(1-2). 272-289. https://doi. org/10.1007/BFoo413603.

Stalnaker, Robert. 1973. Presuppositions. Journal of Philosophical Logic 2(4). 447-457. https://doi.org/10.1007/BFoo262951.

Stalnaker, Robert. 1974. Pragmatic presuppositions. In Milton K. Munitz \& Peter Unger (eds.), Semantics and philosophy, 197-213. New York: New York University Press.

Stalnaker, Robert. 2002. Common ground. Linguistics and Philosophy 25(5-6). 701-721. https://doi.org/10.1023/A:1020867916902.

Stalnaker, Robert. 2014. Context. Oxford University Press. https://doi.org/10. 1093/acprof:oso/9780199645169.001.0001.

Strawson, Peter. 1952. Introduction to logical theory. London: Methuen.

Matthew Mandelkern

All Souls College

Oxford, OXı 4AL

United Kingdom

matthew.mandelkern@all-souls.ox.ac.uk 